\title{
TRAGÉDIA E RISO: “O ABSURDO É A GRAÇA DOS QUE ESTÃO CANSADOS"1
}

\author{
Thaís Leão Vieira* \\ Universidade Federal de Mato Grosso - UFMT \\ thaisleaovieira@gmail.com
}

\begin{abstract}
RESUMO: A intenção com este texto é oferecer uma compreensão do riso em tempos de pandemia como aspecto do humorismo, e não do "simples cômico". Ainda que possa ser prematura a tentativa de definir minha hipótese, refiro-me a uma distinção-chave: não estamos num deboche do outro; estamos rindo é de nós mesmos. $\mathrm{O}$ eixo desse humor é a prática mais sombria, a possibilidade do ridículo que possibilita compreender a vida social séria e o próprio humor de forma complexa.
\end{abstract}

PALAVRAS-CHAVE: Humorismo - Pandemia - Ridículo

\section{TRAGEDY AND LAUGHTER: "THE ABSURD IS THE GRACE OF THOSE WHO ARE TIRED"}

\begin{abstract}
The aim of this paper is to consider laughter as an instance of humourism in pandemic times and not the 'plain comical'. Although the attempt to define my hypothesis may be premature, I refer to a key distinction: we are not in one another's debauchery, we are not making fun of the other; we are laughing at ourselves. The axis of this humor is the darkest practice, the possibility of ridicule that makes it possible to understand serious social life and humor itself in a complex way.
\end{abstract}

KEYWORDS: Humor - Pandemics - Ridicule

Vive-se pior, acho eu, se se viver com medo. [...] O riso subverte o medo. Corrói-o,

1 As aspas no título servem para marcar que a frase é um aforismo do poeta francês Charles Baudelaire (1821-67).

* Professora do departamento de História da Universidade Federal de Mato Grosso e do Programa de Pós-graduação em História/UFMT. Realiza estágio pós-doutoral no Departamento de História da Faculdade de Filosofia, Letras e Ciências Humanas da Universidade de São Paulo, sob supervisão do Prof. Dr. Elias Thomé Saliba, no âmbito do grupo de pesquisa "As narrativas históricas e a polifonia da linguagem humorística brasileira (1930-1960)” (https://humorhistoria.wordpress. com/). 
domina-o, torna-o mais pequeno. É por isso que o doutor Johnson não quer piadas em templos: humor e religião são duas formas inconciliáveis de lidar com a morte - ou com o medo da morte.

RICARDO ARAÚJO PEREIRA

Uma doença contagiosa, uma epidemia, não tem em si qualquer significado, é apenas um microrganismo que ganha significância pelo modo como interfere na vida das pessoas, pelas reações que provoca, pela expressão cultural [...] e pelos valores políticos que adquire [...] A representação dada a uma doença é fruto de uma intensa e complexa negociação social, raramente livre de certa dose de coação cultural, que incorpora e reflete valores e relações de status.

ADRIANA DA COSTA GOULART

Há alguns anos comecei a estudar o humor de um ponto de vista histórico. Desde então, um princípio tem orientado minha reflexão: o de que o humor constitui um elemento fundamental na construção das relações humanas. $\mathrm{O}$ tema inicial dos meus estudos foi o humor em tempos de regime ditatorial no Brasil. Naquele momento, em certa feita, ouvi uma frase que se fixou na memória e se tornou recorrente, como um tipo de disposição para abordar o humor sistematicamente. A frase foi dita pelo professor Jaime Ginzburg, da Universidade de São Paulo, em um diálogo valioso porque esclarecedor e, ao mesmo tempo, instigante e até provocador. Disse-me o mestre: é possível falar sobre o humor sem trivializar a dor. De fato, a compreensão do que disse o professor não é hermética; antes, é de entendimento direto. O problema são os desdobramentos gerados — as consequências —, que revelam a complexidade do raciocínio de Ginzburg. Chamo de consequências os pontos de interrogação que se impuseram à minha reflexão.

Essa contextualização indica um lado do lugar de onde parte minha reflexão, minhas considerações. $\mathrm{O}$ outro lado desse lugar é o momento por que estamos passando (seria um lugar de todos?). Com efeito, da frase dita pelo professor Ginzburg, adveio uma indagação (uma consequência) que, se for relacionada com o presente, expõe os níveis de complexidade com que se lida ao se discutir o humor. Pergunto: como rir em tempos de horror sem banalizar a dor? Ou seja, como não banalizar as vítimas do 
colapso sanitário derivado de uma doença pandêmica e de uma política de saúde (e não só) pandemônica que assolam a população brasileira (mais os que têm menos; menos os que têm mais)? É possível compatibilizar humor e dor? É moralmente correta a atitude do humor-acima-de-tudo perante problemas tão letais?

Essas dúvidas me inquietaram muito na hora de pensar neste texto: no que eu tinha a dizer e na forma como devia dizer. As perguntas são desdobramentos da tentativa de entender e sustentar o princípio-guia dos meus estudos sobre humor em associação com o pensamento do professor Jaime Ginzburg. ${ }^{2}$ Esses elementos de reflexão e indagação estão, então, na base da discussão que faço; mais: levam às questões que se associam aos limites entre comédia e arte em geral ditados desde Adorno. Pensador ligado à chamada escola de Frankfurt — convém lembrar —, Adorno não condena o riso nem a alegria; mas desaprova a futilidade e a arte de repetição que só oferece diversão sem conteúdo. Crê que a alegria propiciada pelo cômico pode levar o indivíduo a lembrar de si, logo contribui para a resistência da subjetividade.

Com efeito, mas a possibilidade suscitada por Adorno tende a se concretizar "quando os atrativos responsáveis pela alegria entram nas obras por necessidade" e, aí, constituem um "elo indissociável com o todo de cada obra" e "mantendo uma ligação imprescindível com o seu tempo". Daí a síntese do filósofo alemão: "Sem o elo dialético com o todo e com a história, a alegria se esvazia do seu caráter subversivo, perde seu potencial libertador, antimitológico" (SANTOS, 2015, p. 106). Assim, o que poderia servir de crítica pode terminar banalizando o assunto abordado. Deve-se considerar também que alguns fatos precisam ser respeitados; e o que houve em Auschwitz é um deles.

Há alguns anos, houve debates sobre a questão de se saber se o fascismo poderia ser apresentado em formas cômicas ou paródicas sem que isso constituísse um ultraje a suas vítimas. É indiscutível o caráter de tolice, de farsa, de artigo de qualidade inferior de que se revestem os elos entre Hitler e seus adeptos de um lado e a imprensa marron e os dedos-duros de outro lado. Não dá para rir disso. A realidade sangrenta não era um espírito bom ou mal de que se pudesse caçoar. Eram ainda os bons tempos quando, com esconderijos e safadezas num sistema de horror, Hasek escreveu Schwejk. Mas comédias sobre o fascismo iam se tornar cúmplices do tolo modo de

2 Ginzburg discute a crônica "Lixo" — sobre o passado ditatorial — em um registro cômico (1995) de Luís Fernando Veríssimo. (GINZBURG, 2012, p. 423-32). 
Fênix - Revista de História e Estudos Culturais

Janeiro -Junho de 2020 Vol.17 Ano XVII no 1 ISSN: 1807-6971

Disponível em: www.revistafenix.pro.br

pensar que considerou esse regime derrotado por antecipação porque os batalhões mais fortes da história a ele se opunham. Acolher a posição dos vencedores não convém aos adversários do fascismo, que têm o dever de não se assemelharem em nada com aqueles que se entrincheiram naquelas posições. As forças históricas que produzem o terror, nascem da própria estrutura social. Não são de maneira alguma superficiais e são poderosas demais para que alguém se ponha a tratálas como se estivesse com a história atrás de si e que os Führers fossem, de fato, os palhaços cujas falas assassinas pudessem equiparar-se a disparates (ADORNO, 2001, p. 16).

Uma má alegria que brota do divertimento, que é um fim em si, que não exige interpretação nem demonstra preocupação com a dimensão histórica e social, tampouco se volta a questões humanas de modo insolente, é a preocupação de Adorno. A vivacidade e a rebeldia da genuína alegria na arte desnudam a artificialidade e a heteronomia presentes não só na má alegria, como também na má seriedade, as quais escravizam, padronizam a produção e a recepção da arte; e estas submetem o artista e o público à obediência irrefletida, à conformidade com a práxis vigente. Portanto, a produção de cada obra deve representar, ao artista, um novo desafio, uma criação única, que se desenvolva em meio à tensão de negar a realidade sem se desvincular dela, de pairar entre a alegria e a seriedade sem se reduzir a nenhuma dessas faces.

Posta essa primeira questão sobre os limites do humor em relação à tragédia, parece-me fundamental marcar uma oposição entre o humor produzido em tempos de pandemia e o humor contemporâneo de maneira mais geral, considerando aqui o que o Gilles Lipovetsky chamou de sociedade humorística. Sem me deter demais nesse debate, creio ser fundamental caracterizar essa oposição. A ideia básica de Lipovetsky em Era do vazio é evidenciar como o humor permeia todas as esferas da vida contemporânea. Repleta de humor, a publicidade nos incita ao consumo exagerado, e esse efeito se estende da mídia à cultura em geral. Em canais de vídeo, em mídias sociais... em nossas aulas (o que se ouve é o mote: "é importante ser engraçado como forma de atrair nossos alunos"). Precisamos usar o humor nas palestras, reflexões, ser fun, ser cool... Rir de tudo como forma de simples prazer (lúdico), que leva ao deboche, e não à crítica. Faz muito sentido aqui o que diz Lipovetsky (2015, p. 15): “[...] a denúncia escarnecedora correlativa de uma sociedade baseada em valores reconhecidos foi substituída por um humor positivo e desenvolto, um cômico adolescente à base de uma extravagância gratuita e sem pretensões". 
Pessoas felizes e sorridentes. Mundos possíveis só em sonho. Chamadas engraçadas. Rimas divertidas. Tudo nos compele a rir como ação que nos salva (mesmo psicólogos e cientistas sociais). Mas cabe ressalva aqui. Não me refiro a esse "humor salvador". Ainda que possa ser prematura a tentativa de definir minha hipótese (relativa ao humor em tempos de pandemia, pelas questões que apresento), refiro-me a uma distinção-chave para mim: não estamos num deboche do outro. Estamos — isto sim rindo de nós mesmos: do absurdo por que passamos neste malfadado 2020.

Convém aqui o pensamento de Michael Billig (2005). Esse autor vê como fácil elogiar o humor para aproximar as pessoas em momentos de puro divertimento criativo. Afasto-me então das teorias do humor mais bem-humoradas analisadas por Billig, advindas dos psicólogos acadêmicos ao fazerem uso de suposições do senso comum sobre a bondade do humor. $\mathrm{O}$ que apresento aqui se move rumo à noção do ridículo como centro da vida social e que localiza, no humor, operação maior e distinta de simplesmente cômico, uma operação fundamental para refletir sobre o riso nos tempos de pandemia. Há razões para dizer que não estamos rindo de um outro; estamos rindo é de nós mesmos. O eixo desse humor é a prática mais sombria, a possibilidade do ridículo que possibilita compreender a vida social séria e o próprio humor de forma mais complexa e menos binária. Cabem aqui as palavras de Ricardo Araújo Pereira (2017, p. 15-6), para quem o humor:

É agressão mas também pode ser curativo, é crueldade mas também pode ser compaixão, é sobrecarga mas também pode ser alívio, é humilhação mas também pode ser apoteose, é leviandade mas também pode ser sensatez, é faísca mas também pode ser extintor. Todas as considerações sobre humor são incompletas (excepto, talvez, esta). É um fenómeno esquivo, ambíguo e resistente à compreensão.

Feitas essas ressalvas sobre as relações entre riso, tragicidade e processo humorístico contemporâneo, volto minha atenção para um vídeo do humorista Marcelo Adnet com Eduardo Sterblitch em comemoração ao quinquagésimo programa da série "Sinta-se em casa", de Adnet e que começou dia 13 de abril. Consideremos o canto do episódio de 19 de junho de 2020:

Calma. Tem que manter a calma. Tem que manter a calma. Só tem jeito se manter a calma. Calma. Tem que manter. Não tem como, desculpa. Não tem como, desculpa. Não tem como. Mais, calma. Calma. Calma. Tem que manter. Não consigo! Tem que manter. Não 
Disponível em: www.revistafenix.pro.br

consigo. Tem que manter. Não dá. Tem que manter. Não dá. Não dá! Não tem condições. Não tem condições. Não tem ministro. Não tem ministro. Como é que vai manter? Não tem ar. Não tem ar (ADNET, 2020, on-line).

Com harmonias sonoras próximas da bossa nova, a canção de Adnet e Eduardo Sterblitch soa como anedota dos pedidos de calma com um desempenho que inverte a lógica do próprio pedido. Cantando em tom crescente, vão do nervosismo ao pânico. O tom jocoso vem do deslocamento da ênfase no canto, pelo pânico, construído mediante a sensibilidade de uma condição que nos faz pertencer ao que Joanna Wilk considerou como comunidade do riso (WILK-RACIĘSKA, 2017). ${ }^{3}$ Os que riem se identificam com a impossibilidade de manter a calma, como quem diz: "não tem condições. Não tem ministro. Como é que vai manter?". O modo operístico de cantar parece querer fazer paródia do jeito bossa-novista, ressaltando a incapacidade técnica e a desafinação. Essa construção alude a uma tradição do humor no Brasil. A referência é aos shows humorísticos que primavam pela canção como forma de produção cômica. Juca Chaves, Chico Anysio, Ary Toledo, Costinha e outros são exemplos de humoristas que exploraram tal combinação. O efeito sonoro do hino, a performance do pânico e o verso "não tem ministro" configura uma sátira política dos tempos atuais no Brasil.

Com efeito, Ricardo Pereira ressalta que um dos elementos próprios do humor é a contradição; é como manter uma forma de irracionalidade racional. Mas como ter calma ante a pandemia que nos enclausura? Como? Afinal, não há ministro da Saúde! Como é que vai manter? O raciocínio humorístico para Pereira procura a contradição, uma tensão provocada entre tema e atitude. Partindo da extrapolação da ideia de perspectiva, a representação é deformada e levada ao absurdo. Não há como ver o revés das coisas, pois já estão arrevesadas. A experiência mais prosaica é o próprio evento absurdo.

Apresentando uma visão da época aos moldes da comédia de costumes, uma espécie de crônica de humor, fazendo rir de valores comportamentais e atitudes diante desse tempo, o Diário de um coronga, de Paulo Vieira, cria tipos e situações típicas de quem está vivendo o isolamento. Em vista disso, no quadro apresentado por ele há uma herança do teatro de revista e de costumes brasileiro que se centrava "na pintura dos

3 Por um viés linguístico, a autora analisa como a comunidade do riso pode se criar dentro de uma dada comunidade sociolinguística, ainda que seus membros possam pertencer a distintas comunidades sociolinguísticas - cf. Wilk-Racięska (2017, p. 109-24). 
hábitos de determinada parcela da sociedade contemporânea" (FARIAS; GUINSBURG; LIMA, 2006, p. 88). A relação com o popular das comédias de costume se evidencia no vocabulário: misturam-se o discurso prosaico e o cantado; no plano do conteúdo, singularizam-se pela evidente identificação entre o exposto e o público.

Desde o início da quarentena, Vieira começou a publicar uma série de posts que batizou de Diário do coronga. A voz meio trêmula, o sotaque interiorano e o português falado, muitas vezes, de forma agramatical são algumas características das personagens Mãe e amigas, Niedja e Saionara. A tentativa de trazer o público mais popular é traduzida na métrica e construção dos diálogos: característicos do grupo de pessoas que as personagens representam e que são familiares ao público. Feitos com áudios do software WhatsApp, trazem uma dona de casa, a mesma personagem que o ator fazia no quadro "Isso é muito minha vida", do programa Se Joga, mandando mensagens para seus contatos e falando com as amigas. Em um deles, diz:

Niedja, será que esse negócio do "coronga" não é o fim dos tempos, não? [...] Porque, na Bíblia, fala que Deus não vai mais acabar o mundo com água, vai acabar com fogo. Então, acho que Deus está sendo muito é do esperto: esperando nós todos nos lambuzarmos no álcool para ele só vir e jogar um fósforo (VIEIRA, 20 mar. 2020, online).

O Diário de um coronga, quando trata de assuntos sociais, opera na natureza crítica e até satírica para ridicularizar um cosmos marcado por tensões e diferenças sociais. No programa de 22 de março, a Mãe pergunta: "Niedja do céu! Você não sabe quem não tá de quarentena? Minhas dívida, minhas conta, meus boleto, minhas cobrança!” (VIEIRA, 22 mar. 2020, on-line). No vídeo publicado em 22 de março, a mulher interpretada por Paulo fala sobre a diferença de isolamento perante a população pobre:

Saionara - Como cês tão de quarentena? Só curtindo isolamento? Eu tô aqui isoladinha, bem quieta.

Mãe - Saionara, para de falar que você está em isolamento, isso é coisa de rico. Rico é que tem a casa grande, aí fala que tá isolado. Você está aí com quinze parentes dentro de um cômodo, você não está isolada, Saionara!, você tá amontoada! Você tá mocozada! Pobre não se isola, pobre se amontoa, Saionara! Para de querer ser blogueira! (VIEIRA, 22 mar. 2020, on-line). 
Característico do teatro de revista, o compromisso com a atualidade traçava um panorama cômico das atividades do ano. Muito comum foi o quadro das doenças ${ }^{4}$ no qual a febre amarela, a peste bubônica, a varíola e outras apareciam personificadas. Assim, situações cômicas ante o panorama cotidiano vão aparecendo diante da atmosfera de medo e colapso social, como se lê nesta passagem:

Mãe - Essa quarentena do governo, eu acho que é um projeto deles pra eu explodir de comer. Porque aí eu comprei as coisas no mercado que dava pra um mês. Eu já comi tudo. Eu vou ficando ansiosa, vou vendo as notícia. O mundo vai acabar, cada notícia ruim que dá é um lanche de um dia que eu como, quer dizer... já acabou tudo. Então assim... se o Corona não me matar, a gordura vai (VIEIRA, 17 mar. 2020).

No esquete, a Mãe ridiculariza o cotidiano e trata do vício da gula - mau costume destes tempos - interpretando seu entorno diante da situação de rigidez imposta pela pandemia. A impossibilidade de estabelecer expectativa positiva para a doença ante o violento impacto da moléstia, gerado pela governabilidade do Estado brasileiro em relação às medidas sanitárias, é componente de cenas satíricas quando a Mãe ridiculariza a maleabilidade das ações de combate à doença covid-19,

Niedja - Mulher, simbora sair. O presidente liberou já.

Mãe - Liberou não sei quem, Niedja. Eu não tô dentro de casa escondida de Bolsonaro. Eu tô aqui escondida é de coronga. Eu aqui é igual na arca de Noé. Eu só saio daqui quando alguém me der certeza de que eu posso pisar em terra firme. Enquanto não aparecer a pombinha na minha janela com uma folhinha verde no bico, eu não saio.

Niedja — Ôxe, mulher! Mas o comércio tem que abrir! Como é que a pessoa vive sem dinheiro?

Mãe - Como é que vive sem dinheiro, Niedja? Vivendo igual nós vive! Eu, pra viver sem dinheiro, eu faço assim: eu respiro e sigo a vida. É assim que vive sem dinheiro. Não tem novidade nenhuma, pra

4 "Em 11 de junho de 1892 estreava, no Teatro Apolo, na Capital Federal da recém-República, a revista de ano $O$ Tribofe, de Arthur Azevedo, peça de teatro satírica que passava em revista os principais acontecimentos do ano anterior. A partir do olhar de uma família vinda do interior do Brasil e de passagem pelo Rio de Janeiro, o espectador rememorava o pretérito recente, o ano de 1891, tendo como cenário a cidade. Vários eventos que marcaram o ano anterior figuraram no decorrer dos quadros da peça: a crise econômico-política, que ficou conhecida como encilhamento, as doenças infectocontagiosas responsáveis pela alta mortalidade na capital, como a febre amarela e a varíola, os jornais de maior circulação e os que apareciam e faliam, os grandes espetáculos teatrais que deram "enchentes" (como eram denominadas as casas cheias no teatro), que se misturavam aos tipos urbanos como apostadores de cavalos, jóqueis, especuladores, cocotes e pessoas comuns, circulando por localizações específicas da cidade, como o hipódromo Derby Club, a Praça XV, o Passeio Público, a Rua do Ouvidor..." (SICILIANO, 2014, p. 210) 
mim, viver sem dinheiro, Niedja. Novidade pra mim é morrer. E eu tô evitando esse ano. E se eu fosse você eu evitava também, viu Niedja? Ô, Niedja! Você não morre não, que eu te mato, hein? (VIEIRA, 25 mar. 2020, on-line).

Contrariando o regime de quarentena e isolamento próprios das medidas de segurança recomendadas pela Organização Mundial de Saúde, a presidência da República decidiu, apesar da extrema gravidade,

contra todas as orientações técnicas dos especialistas nacionais e internacionais, inclusive da Organização Mundial da Saúde (OMS), iniciar a campanha intitulada "O Brasil não pode parar". Veiculada em diversas mídias (vídeo em anexo), campanha insta os brasileiros a voltarem a suas atividades normais, sem estar embasada em documentos técnicos que indiquem que essa seria a providência adequada nesse momento (AÇÃO CIVIL, 2020, on-line; grifo meu).

Ante a falta de resposta pública e a impossibilidade de socorrer a população, as denúncias de comportamentos e as decisões - por exemplo, cada qual cuidar de se salvar ("novidade pra mim é morrer") dados os serviços de combate à pandemia e o cotidiano que com esta impôs — provocaram uma reação humorística. Mais que deixar as emoções em suspenso, como uma espécie de alienação - é o contrário, o riso do absurdo - , tal reação faz, da zona de reflexão, matéria risível ante o real-absurdo.

Com efeito, em Diário de um confinado, comédia de doze episódios criada por Bruno Mazzeo e Joana Jabace e produzida pela Rede Globo, presenciamos a conjugação da desordem, do desencadeamento linear, do romper com a noção de tempo na perda da rotina. No episódio 9, após fazer ressalvas de que havia chegado o sábado - quando algo finalmente poderia acontecer —, afirma o protagonista Murilo (Mazzeo): “Aí chegou o sábado, que, na quarentena, nem faz tanta diferença, já que agora tudo virou um grande aglomerado de horas insuportáveis que nos privam da solidão. Mas que não fazem companhia de fato". O efeito cômico tem como alicerce o exagero da perspectiva e da relatividade do real.

Mazzeo não se restringe a criticar a obsessão pelo mundo pós-pandemia, por um futuro promissor ao qual se dirige o presente. Sua crítica se dirige à atitude de valorização inconteste do passado, à veneração do mundo pré-pandemia. No episódio “Academia", Murilo evidencia que seu sedentarismo já existia bem antes, de tal modo que organizar uma rotina, pedir pizza, faxinar a casa, conviver com vizinhos, fazer terapia, tudo se torna tema do ridículo do absurdo, evidenciado nos gestos do 
Disponível em: www.revistafenix.pro.br

protagonista. O olhar exausto, o corpo que tenta encontrar normalidade na rotina repetitiva do apartamento (marcada na abertura dos episódios em que Murilo faz um traço no espelho do banheiro, indicando mais um dia de isolamento), os ombros caídos (mas que buscam encontrar ânimo para se levantar), na insociabilidade: tudo desperta nossa sensibilidade como sentimento de absurdidade, tudo faz nos darmos conta de nós mesmos.

O que nos impede de levar a sério a situação trágica nesses instantes tão corriqueiros? Se pusermos de lado o que nos desperta a sensibilidade ao trágico, ao que nos comove ante o que vivemos, então o que vier pode se tornar cômico; e por instantes podemos nos esquecer de ver a nós mesmos, de nos observarmos como moldura. São exemplares as palavras de Murilo no episódio 8, em que ele resolve fazer comida e descobre suas memórias de comer, em família, uma comida que pensava ter sido feita pela tia Rita (interpretada por Arlete Salles), mas que não eram. Bem intencionado em sua conduta de aprender a cozinhar, ele diz: "A boa notícia é que hoje em dia tem tutorial para tudo na internet. A má notícia são todas as outras”. A supor-se que estivéssemos vendo um espetáculo cujo objeto do riso fosse o outro, um externo a nós mesmos, então o cômico seguiria aquilo a que Pirandello considera fundamental para a comédia: a insensibilidade do espectador. $\mathrm{O}$ que nos interessa aqui é que estamos diante de um riso que não pode ocorrer do lado de fora. Neste, estão os não confinados. Mas rimos com o que nós mesmos sentimos. De fato, "as más notícias são todas as outras".

A saga de Murilo se inicia com um gesto simples e corriqueiro: pedir pizza, porém enquanto dialoga com a mãe, Marília (Renata Sorrah), sobre os riscos de fazer tal pedido.

Mãe - Pediu pizza, filho? Tá querendo se matar?

Murilo - Oh, mãe. Eu vou pedir pizza de calabresa, não vou pedir pizza de cianureto.

Mãe - Então pede uma logo [de] sabor Corona.

Murilo - Vou pedir metade paranoia, metade loucura com bastante orégano. Pronto!.

Mãe - Isso, Murilo! Vai brincando, vai! Vai brincando, Murilo! Vai brincando!

Murilo - Mãe, mãe! Eu tô atento. Quando chegar, vou passar álcool. Mãe - não, não! Não adianta. Ontem no grupo colocaram no grupo da hidroginástica que esse vírus ele é transmitido até pelo cheiro da comida.

Murilo [risos] - Pelo cheiro, mãe? Mãe, por favor, grupo de zap não é exatamente uma fonte das mais confiáveis. 
Disponível em: www.revistafenix.pro.br

Mãe - Não, não é! O genro da Abigail, ele conhece um médico tope, de um hospital tope em São Paulo...

Murilo - Todo mundo conhece um médico tope, de um hospital tope de São Paulo. Parabéns pro genro da Abigail.

Mãe - É... ele disse que esse vírus fica no papelão por dois anos. Dois anos!

Murilo - Para de acreditar em tudo que você recebe. É muita coisa, tem que ficar atenta, tem que checar as fontes.

Mãe - Aah, tá bom, tá bom, tá bom! Recebe aí o entregador. Abraça ele, beija, convida ele pra comer a pizza e dormir abraçadinho com você. Faz isso. Eu desisto. [Murilo, olhando para a câmera, diz:] A minha mãe é muito ativa nas redes sociais. Ela participa de vários grupos no zap, que dizer, ela é minha fonte segura de fake news. Eu não preciso nem checar. Se dona Marília compartilhou, é fake (DIÁRIO DE UM CONFINADO, 2020, episódio 1, on-line).

O tédio que motiva risos em tempos de pandemia não encontra consolo nem proteção no outro. Ao contrário: estamos tomados por uma experiência profunda de dor e separação, de um luto ininterrupto, sem remissão, sem poder viver o luto coletivo com a negação sistêmica da pandemia na realidade brasileira. Como na há correlação equivalente entre perdas e sentimentos, então não há possibilidade de reparação. Alheios a um projeto coletivo - o bem comum —, seguimos negando a morte como forma de manter uma juventude perene.

O riso em Diário de um confinado aponta uma superação da melancolia provocada pela cumplicidade dos "confinados". O caráter do riso compartilhado, cúmplice da situação e do contexto de produção é fundamental em Diário... não só pelo texto, mas também e sobretudo pelas gags humorísticas de Bruno Mazzeo, pela performance, pela voz "cansada, ansiosa e nervosa", fundamentalmente pela performance do olhar. $\mathrm{O}$ espectador é instigado por estímulo de participação dado por Mazzeo ao olhar para a câmera. É como se a intenção de sentido do seu olhar fosse esta: "Eu sei que vocês também estão confinados". O público é posto em uma situação de diálogo com a cena e se descobre espectador desterritorializado de seu lugar de espectador; ou seja, vê-se posicionado na cena como princípio ativo na obra.

Com efeito, o artifício de Mazzeo não é novo em si. Poderíamos pensar aqui no espectador como princípio ativo das ações - como na ideia de espectador emancipado em Jacques Rancière - no campo da performance. O que pretendo afirmar é que a condição participativa para o espectador só funciona no caso de Diário... pelo riso do absurdo. Em especial em $O$ riso (que analisa como, mediante fenômenos sutis de impregnação, combinação ou mescla, a comicidade pode se insinuar como movimento), 
Bergson salienta a função do riso - sempre um pouco humilhante para quem é seu objeto - como uma espécie de trote social. Aqui, o que me parece central é que não estamos rindo de atitudes ou situações tal qual riríamos de um espetáculo que vemos do alto de nosso camarote. Se, em dada teoria do riso, a comédia tem a intenção de rebaixar, humilhar, portanto de corrigir os defeitos do outro, então como explicar que vivemos uma tragédia pandêmica e rimos?

Uma tarefa trivial como comprar pizza é alvo de um agrupamento de medidas que faz de algo outrora banal algo notável agora. Parece ser o ridículo de que tudo se tornou absurdo. O absurdo mostra a precariedade dos modos de significar, uma falsidade da ordem lógica. O cômico aparece numa posição que deflagra uma expectativa já frustrada e que agora é subvertida. Trocadilhos e imagens que advêm deles recaem nas piadas que se ajustam ao absurdo do real. Com efeito, Murilo inicia o episódio 5 do Diário..., "Rotina", dizendo:

Meu fuso tá meio doido. Na verdade, eu tô sem fuso. Ou seja, "confuso". "Com-fuso" [fazendo gesto com as mãos indicando o trocadilho]. Quando a gente tá confinado, sozinho assim, é importante criar uma rotina. Pra não pirar, tem que ter o dia bem organizadinho. Que é o que eu tô fazendo. Não o dia organizadinho. O pirar! [ênfase na voz] (DIÁRIO DE UM CONFINADO, 2020, episódio 5, on-line).

O mesmo episódio mostra Murilo em uma sessão com uma terapeuta, Leonor (Fernanda Torres). Ele, então, questiona sua ausência de rotina. O humorismo se revela no absurdo que vemos na condição da terapeuta: também ela está sem rotina. Eis como se desdobra a passagem do diálogo entre terapeuta e paciente:

Leonor - Murilo, eu acho que você precisa de rotina.

Murilo - Pois é... eu também tô achando, mas...não é fácil, né?

Leonor - Não é fácil... Nossa!

[Entra o filho de Leonor]

Marco Antonio - Ôoo mãeeee

Leonor — [virando-se para trás diz:] Sai!

Murilo - Se pelo menos eu tivesse aqueles compromissos, acordar cedo [ôooooo mãeeeeee], ir para o trabalho.... [ÔOOOOO mãeeee]

Leonor — Pode falar, eu tô ouvindo, não tô ouvindo mais ninguém aqui, vai!

Marco Antonio - Mãe, é a vovó, ela quer falar com você.

Leonor - Eu não acredito! Acabei de falar com ela. Desculpa!

[Murilo tenta falar sem êxito]

Leonor - Ela tá lá no telefone ainda? Eu já vou ligar, fala pra ela.

[Leonor olha furiosa] 
Marco Antonio - Mãe, eu já falei, cara. Mas ela tá falando que você não resolveu, de não sei o quê, de não sei que lá, fala lá com ela, não tô conseguindo resolver.

Leonor - Faz um favor, Marco Antônio. Você manda sua avó pastar! [Murilo permanece impaciente ouvindo tudo aquilo e olha assustado] [Leonor volta-se para Murilo]

Leonor - Aaah! Desculpa, Murilo! Desculpa, mas é que.... eu tô aqui e fica tudo em cima de mim... você não tem ideia, é uma coisa impressionante, sabe?

Murilo - Quer marcar outra hora, Leonor? A gente...

Leonor - Tá... é melhor... tá... Desculpa... Enfim... mas... põe na cabeça..... você tá precisando é de hormônio do bem-estar. É endorfina, é morfina... Não! Morfina, não! É endorfina, serotonina, melatonina e ROTINA, tá? Tchau!

[Desliga imediatamente o computador] (DIÁRIO DE UM CONFINADO, 2020, episódio 5, on-line).

O que antes era algo não revelado para nós agora é revelado pela confusão dos espaços público e privado. Há um cômico compartilhado, é possível rir do desespero de Leonor para tentar encontrar o mínimo espaço "público", dentro de sua casa, mas não conseguimos apontar o dedo para ela como se nós mesmos não fôssemos Leonor e Murilo. Não há um distanciamento entre o sujeito e o objeto do qual se ri, em que as tragédias se revelam cômicas, seja nas expressões irônicas ou nos trocadilhos ruins, como no episódio 6, "Date". Com efeito, nesse episódio, Murilo está muito melancólico por estar sozinho na pandemia e diz: "Sozinho é muito difícil. Eu acho. É quarentena, mas poderia muito bem se chamar de 'carentena', de carente [faz uma pausa, olha para o espectador e sorri de forma cúmplice]".

Em seu ensaio "O humorismo" (1996), o dramaturgo italiano Luigi Pirandello define o humorismo como o sentimento do contrário. Isso se difere da percepção do contrário que se alinha às teorias clássicas do humor. $\mathrm{O}$ cômico é alguma coisa de errado na sequência natural dos fatos. O exemplo típico é de alguém que está na rua andando e que caí. Mas rir dessa quebra dos acontecimentos requer que o "erro" não nos envolva, e que, perante o "erro" do outro, nós que não cometemos "erros" sintamo-nos superiores: aptos a ver com olhar de superioridade as contradições do outro (ECO, p. 253).

Pirandello se reporta a uma personagem emblemática da literatura para distinguir humor de comicidade: Dom Quixote. Para o dramaturgo, o personagem de Cervantes cria em nós uma sensação de pena e admiração, que Pirandello chama de "sentimento do contrário", dado quando, via reflexão, enuncia-se o humor para nós. O 
humorismo no dramaturgo é a reflexão que se exercita antes e após o ato cômico que considera a possibilidade do contrário, mas nega a superioridade e o distanciamento (SALIBA, 2002, p. 25). Pirandello vê o humor como algo que demanda, necessariamente, um exercício de reflexão que provoque o riso: não de repulsa; sim de compreensão.

Embora o humor remonte, ao menos, à antiguidade, é a natureza ambígua do homem moderno que o caracteriza segundo Pirandello. A personagem humorística sente e sofre porque o riso no humor, muitas vezes, provém do sofrimento; não da comicidade. Não por acaso, ele salienta um equívoco na interpretação do humorismo: pensar que o escritor humorista é quem faz rir. O cômico, a sátira, o grotesco, a farsa, a caricatura, tudo faz rir; todavia, não se confundem com o humor. No processo de criação humorística, o sentimento do contrário é essencial — diria Pirandello — porque se parte do princípio da intervenção da reflexão que evidencia o contrário de qualquer ilusão. Assim, uma reflexão acompanha o riso do humorismo.

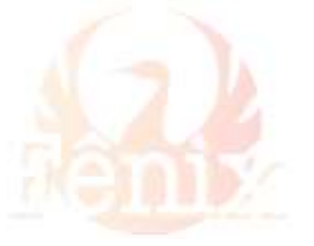

Na concepção de toda obra humorística, a reflexão não se esconde, não permanece invisível, isto é, não permanece quase uma forma de sentimento, quase um espelho no qual o sentimento se mira; mas se the põe diante, como um juiz; analisa-o, desligando-se dele; descompõe a sua imagem; desta análise, desta decomposição, porém, surge e emana um outro sentimento: aquele que poderia chamar-se, e que eu de fato chamo o sentimento do contrário (SALIBA, 2002, p. 132).

Pirandello cita o exemplo da anciã que tinge os cabelos e se veste com roupas de corte mais jovial, o que pode provocar o riso: aquilo que não condiz com o que a senhora usa para parecer mais nova em idade provoca o que Pirandello chama de "advertência" do contrário, provocador do riso. Aí consistiria o ato cômico. No entanto, se refletirmos sobre o ato da senhora, os motivos pelos quais ela adotou tais procedimentos, se refletirmos sobre sua situação e sua luta contra o tempo, então surgirá um sorriso amargo; e da advertência vão emanar um sentimento do contrário (PIRANDELLO, 1996). A personagem não está mais distante de mim, mas eu tento entrar em seu universo. O riso se transformaria em sorriso, misturando-se com a piedade. Pirandello acentua que, para passar do cômico ao humorístico, é necessário passar do distanciamento e da superioridade: características clássicas do cômico (ECO, 1989). 
Como último diálogo com Pirandello, convém sua reflexão sobre os humoristas: estes põem em relevo a verdadeira realidade, as particularidades comuns, a materialidade da vida, que sabe o humorista ser complexa e variada, à qual não cabe uma lógica harmoniosa concebida aos escritores comuns (ECO, 1989).

O humorismo consiste no sentimento do contrário, provocado pela especial atividade de reflexão que não se esconde, que não se torna, como comumente na arte, uma forma do sentimento, mas o seu contrário, mesmo seguindo passo a passo o sentimento como a sombra segue o corpo. $\mathrm{O}$ artista comum cuida do corpo somente: o humorista cuida do corpo e da sombra, e às vezes mais da sombra do que do corpo (ECO, 1989, p. 169-70).

Umberto Eco salienta a consciência do ridículo do real quando representamos, mas é na reflexão que a distorção da realidade se manifesta como realidade distorcida. Por romper com convenções e máscaras, a forma humorística age como uma

[...] metalingüística sobre a linguagem petrificada com que representamos e explicamos a vida. Mostra-nos (nós ocultos por máscaras lógicas e morais) como contrários aos que somos e, portanto, como cômicos. Mas exatamente porque tenta entender a razão desta comicidade torna-se reflexão humorística. Mas como não havia razão para rir quando se estava dentro da situação, da mesma forma existem pouquíssimas razões para sorrir quando a arte nos afasta da situação, desdobra o homem e o ator, o ator e o personagem. Isto é, pode-se até sorrir, mas as razões pelas quais se sorri são as mesmas pelas quais se chora (grifo nosso) (ECO, 1989, p. 258).

A atividade de reflexão é "fruto da tristíssima experiência da vida", aquela que “determinou a disposição humorística do poeta”, como afirma Pirandello (1996, p. 1345). "Toda vez que me encontro diante de uma representação realmente humorística" diz ele —, "me sinto como se mantido entre duas (coisas): gostaria de rir, rio, mas o riso me é turbado e impedido por alguma coisa que emana da própria representação" (PIRANDELLO, 1996, p. 136). Assim, o humorismo é provocado pela reflexão porque conserva a possibilidade do contrário, mas elimina nosso distanciamento e nossa superioridade. É por isso que podemos sorrir por motivos que podem nos fazer chorar.

Em que pesem os riscos de se fazer análises no meio do "furacão pandêmico" e ainda mais com tom ensaístico, minha intenção com este texto foi oferecer uma compreensão mínima do riso em tempos de pandemia como aspecto do humorismo, e não do "simples cômico". Algumas pistas me levaram a tal, a exemplo do que diz 
Disponível em: www.revistafenix.pro.br

Billig: "existem boas razões para afirmar que a compreensão do humor é necessária para compreender a vida social séria". Com efeito, o humor hoje é uma força significativa. Em tempos tão difíceis, não se discute que vamos ter muito com que nos ocuparmos intelectualmente: é preciso compreender como e por que temos nos dedicado ao riso em diferentes partes do mundo. Assim, há mais uma razão — mais geral — para conectar o humor à seriedade e que está na base do argumento deste estudo: riso em tempos de pandemia quebra o paradigma da superioridade, do distanciamento, pois somos, antes de tudo, sujeitos e objetos desse riso.

Para concluir, convém a reflexão do autor cujo pensamento me inspira metodologicamente para desenvolver a reflexão que estou fazendo (da qual este artigo faz parte), mas não sem risco histórico. Obviamente, meu trabalho está aberto, isto é, passível e suscetível de revisão conceitual e metodológica. Assim, replico o pensamento de Elias Thomé Saliba (2002, p. 26) acerca do riso no Brasil do fim do século XIX, começo do século XX. Diz ele: "Possibilitando ao sujeito representar o mundo como se estivesse representando a si próprio", o humorismo "transformava-se na mais importante atitude estética"; até pode ser que fosse "a única capaz de servir de guia naquela obscura atmosfera fin-de-scièle de ruína das noções públicas da linguagem, incapazes de acompanhar o ritmo vertiginoso das mudanças". A impressão era de que "o humor ajudava os brasileiros a viver" ao lhes dar "uma espécie de ética ilusória e efêmera capaz de colimar, ao menos provisoriamente, os obstáculos e as dificuldades que se esgarçavam naquele momento crítico" (SALIBA, 2002, p. 70).

\section{REFERÊNCIAS BIBLIOGRÁFICAS}

AÇÃO CIVIL — pedido de medida de isolamento social, 6 de abril de 2020. Disponível em: http://www.mpf.mp.br/pa/sala-deimprensa/documentos/2020/ACP_MedidasdeIsolamentoSocialCovid19assinada.pdf Acesso em: 5 jul. 2020.

ADNET, Marcelo. Instagram Marcelo Adnet oficial. Disponível em: https://www.instagram.com/p/CBo1zyCh622/. Acesso em: 10 jul. 2020.

ADORNO. A arte é alegre? In: PUCCI, B.; RAMOS-DE-OLIVEIRA, N.; ZUIN, A. A. S. (Org.). Teoria crítica, estética e educação. Piracicaba: ed. UNIMEP, 2001. 
BILLIG, Michael. Laughter and ridicule. Towards a social critique of humour. London: Sage Publications, 2005.

DIÁRIO DE UM CONFINADO. Série, $1^{\mathrm{a}}$ temporada. Disponível em: globoplay.globo.com Acesso em: 28 jun. 2020.

ECO, Umberto. Pirandello Ridens. In: ECO, Umberto. Sobre os espelhos e outros ensaios. Rio de Janeiro: Nova Fronteira, 1989.

FARIA, João Roberto; GUINSBURG, Jacó; LIMA, Mariangela Alves de (coord.) Dicionário do Teatro Brasileiro: temas, formas e conceitos. São Paulo: Perspectiva/Sesc, 2006.

GINZBURG, Jaime. Memória da ditadura em Caio Fernando Abreu e Luís Fernando Veríssimo. In: GINZBURG, Jaime. Crítica em tempos de violência. São Paulo, Bauru: Edusp, 2012.

GOULART, Adriana da Costa. Um Cenário Mefistofélico: gripe espanhola no Rio de Janeiro. 2003. Dissertação (mestrado em história) — Universidade Federal Fluminense, Niterói, RJ.

LIPOVETSKY, G. A era do vazio. Ensaio sobre o individualismo contemporâneo. Barueri: São Paulo: Manole, 2005.

PEREIRA, Ricardo Araújo. A doença, o sofrimento e a morte entram num bar uma espécie de manual de escrita humorística. Rio de Janeiro: Tinta da China, 2016.

PIRANDELLO, Luigi. O humorismo. São Paulo: Experimento, 1996.

SALIBA, Elias Thomé. Raízes do riso - a representação humorística na história brasileira: da belle époque aos primeiros tempos do rádio. São Paulo: Companhia das Letras, 2002.

SANTOS, Luiz Fernando dos. O soterramento da autonomia: música e resistência, segundo Theodor W. Adorno. 2015. Dissertação (mestrado em Filosofia) - Escola de Filosofia, Letras e Ciências Humanas, Guarulhos, SP.

SICILIANO, Tatiana. Pintura e teatro: a pedagogia do olhar n'O Tribofe de Arthur Azevedo. Sociologia \& Antropologia, versão on-line, Rio de Janeiro, v. 4, n. 1, jan./jun. 2014, p. 207-32. Disponível em: https://www.scielo.br/scielo.php?script=sci arttext\&pid=S2238-38752014000100207

VIEIRA, Paulo. Isso é muito minha vida. Instagram paulo.vieira.oficial. Disponível em: https://www.instagram.com/p/B9-E-K3nt7n/ Acesso em: 15 jun. 2020.

WILK-RACIĘSKA, Joanna. La definición de comunidad de risa reformulada. In: FERREIRA, João Pedro Rosa; VIEIRA, Thaís Leão (Org.), Humor, língua e linguagem: representações culturais. São Paulo: Verona, 2017, p. 109-24. 